\title{
Citizen and state in the philosophy of Spinoza
}

Suppose that an intellectualistic theory of human wellbeing is true; that is, that human beings are better off to the extent that they possess knowledge. Now suppose that the highest purpose of society is to make each human being in it as well off as possible. Finally, suppose that the vast majority of human beings in society possess, as their most important beliefs-beliefs that guide their lives-ideas that are among the least rational of all ideas. On the first supposition, such people are not thriving. Their lives are hardly characterised by knowledge at all. Here are two possible ways in which society might help them: it might, step-by-step, transform the relevant ideas, making them more and more rational until, finally, there are the most rational beliefs there could be in a given citizen. Alternatively, society might, while leaving the least rational beliefs untouched, cultivate other ideas-ideas that are rational-so that eventually these other ideas become motivationally as powerful as the original, irrational beliefs, which citizens finally discard only when they need them no longer. The first kind of transition may seem appealing on the face of it: it seems harmful, under the given theory of wellbeing, to be guided by maximally irrational beliefs and so better to get rid of them as soon as possible and to be guided by the most rational beliefs one can at a given moment. This might seem to be especially true for Spinoza, who holds versions of all of the background suppositions here and, in addition, famously insists that only very few people attain a significant level of wisdom. After all, for Spinoza, there is a question whether, following the second path to greater wisdom, many people will ever acquire sufficiently powerful rational ideas; they may never be able to set aside their powerful, irrational motivating beliefs.

I will argue here, however, that the first kind of transition is not open to Spinoza and that in fact he conceives of citizens' transition to reason primarily in the second way. Safety and cooperation are, for Spinoza, necessary means to knowledge of any degree. Only two kinds of human states reliably bring people not to threaten others and to cooperate: states in which our behaviour is guided by ideas of miracles, the least rational beliefs; and states in which our behaviour is guided by ideas of reason, the most rational beliefs. ${ }^{1}$ Spinoza's convictions in psychology and political philosophy suggest that for ordinary people to lose imaginative religious ideas without yet having gained a sufficient degree of reason would be for them to lack any reliably social motive, that is, any motive to cooperate. Such 
a change would cause ordinary people, and those who live with them, to lose the benefits of society altogether.

My thesis is ambitious, and risky, in that it characterises Spinoza's views as a whole, rather than through any particular work. In defending it, I will draw upon several different works and try to explain the connections between them. The first section here will explain the suppositions. The second will present textual evidence supporting the claim that Spinoza conceives of these two kinds of transition to greater rationality. The third section will set the conditions that Spinoza requires for peace in society together with his conception of how it is possible for citizens to meet those conditions. It will become apparent at the end of the third section, I hope, that Spinoza's convictions in psychology and politics imply that citizens should move to greater rationality primarily by means of opposing rather than transforming their harmful passions. Of course, it is one thing to show that Spinoza's views imply this conclusion and quite another to show that Spinoza himself draws it. A concluding section will present some slight evidence that he does so.

\section{The suppositions}

Although all his works are complex-and the Theological-Political Treatise (TTP) in particular offers views of reason, religion, and the state that challenge readers to find a consistent position-I think that there is relatively clear and straightforward evidence that he maintains versions of the suppositions consistently throughout his writings. In the early Treatise on the Emendation of the Intellect (TdIE), Spinoza associates his own happiness with a nature characterised by understanding and then goes on to say that the purpose of society is to bring as many people as possible to such a nature:

I aim, therefore, at this end: to acquire such a nature and to strive that many others might acquire it with me. It is for my happiness that I work so that many others will understand in the same way that I do, so that their intellects and desires unite harmoniously with my intellect and desire. So that this might happen, it is necessary to understand as much about nature as is necessary for the attainment of such a nature, and, next, to form a society of the desired kind, so that as many people as possible, as easily and securely as possible, may attain it. (TdIE $\$ 14$ / G2:8-9)²

Similar views may be found in the Ethics, where Spinoza's intellectualism is most fully developed. Although the Ethics focuses on individuals for the most part, a similar conception of the common good may be found there, at E4P54S, which also shows evidence of the role of religion as a first step toward a life guided by reason. As I understand that step, it is a step away from danger, fear, and chaos and into safety and cooperation. So, of particular importance to me is Spinoza's conviction that the religious are easily led, whereas those guided by other passions, especially anger and hatred, are not:

No wonder, then, that the prophets, who cared about the common good and not that of the select few, commended humility, repentance, and reverence so much. Really, those who are subject to these affects can be led much more easily than others, so that in the end they can live under the guidance of reason, that is, they can be free and enjoy the life of the blessed. (E4P54S) 
Finally, Spinoza defends freedoms of speech and thought in Chapter 20 of the TTP on the grounds that they promote rationality:

It is not, I say, the end of the State to change men from rational beings into beasts or automata, but the opposite, that their mind and body may perform their functions safely and that they may use this same reason freely, and that they should not quarrel in hatred, anger, or deceit, or hold unkind feelings toward one another. The end of the state, therefore, is really freedom. (TTP, ch. 20 / G3:241)

The TTP, as I have mentioned, is notoriously difficult to interpret. Some of what Spinoza writes in the TTP suggests that a life of religion may be just as good as a life of reason. Moreover, in several places, both in the TTP and in the Political Treatise (see, for example, the final paragraphs of Chapter 1 of the latter), Spinoza writes that the end of the state is security and convenience; there, freedom is not mentioned. The passages about the life of religion being as good as the life of reason present a problem too detailed to address here, and it may well be in the end that they simply aren't consistent with other passages that suggest that the life of reason is what we aim at for all citizens. I do not think, however, that the other group of aforementioned passages, passages about the end of the state, pose a deep problem for finding a consistent position in Spinoza. Spinoza holds that the state brings cooperation and security, which are necessary for bringing as many people as possible to the greatest degree of rationality possible. So, the state's immediate end is security, but that security has a further purpose: the greater rationality of its citizens, or, what amounts to the same thing for Spinoza, their freedom. ${ }^{3}$ These views are clearest perhaps in paragraphs 4 and 5 of Chapter 5 of the Political Treatise, where, by referring to the lives of subjects in different states, Spinoza distinguishes between states that bring security, but not the further end of reason to their citizens, and states that bring genuine peace:

A state whose subjects do not take up arms because they are terrified is better said to be not at war than to have peace. For peace is not the absence of war but is a virtue that arises from strength of mind [...] When I say, then, that the best rule is that where men pass life harmoniously, I understand human life, which is defined not merely by the circulation of blood and other things common to all animals, but most of all, by reason, the true virtue and life of the mind. (TP, ch. 5, \$4-5 / G3:296)

\section{The two kinds of transition}

I will argue that Spinoza conceives of an ordinary citizen's transition to greater rationality as one that occurs in one rather than another of two ways. In order to show the relevance of the issue, I will now introduce several passages from Spinoza's account, in the Ethics Part 5, of what we can do to manage the passions. He defends accounts of both sorts of transition there. My claim about political states, then, is that, of two kinds of transition that Spinoza regards as possible for a given mind, he only finds one appropriate for the ideas that guide most citizens.

The first kind of transition is one on which a given, irrational idea is made more highly rational. Spinoza conceives of some passions as more harmful than others, and they typically motivate behaviour as well, so a passion will be a good example of such an irrationality: we can overcome hate, which is both an inadequate 
idea and a harmful passion, by coming to know the passion itself more clearly. Spinoza defends the possibility of such understanding at E5P2-P5, at one point recommending without qualification that we should try to understand our passions in this way:

We should work especially hard, in order to know each affect clearly and distinctly, insofar as it can be done, so that thereby the mind may be determined from an affect to thinking those things that it perceives clearly and distinctly and in which it may be completely content; and also so that the affect may be separated from the thought of an external cause and joined to true thoughts. (E5P4S)

In the case of hatred, the final step is notable. Hatred is sadness accompanied by the thought of an external cause (E3P13S). A critical step in making the idea that is hatred clearer is to separate it from that thought and so to transform it.

The second kind of transition is a transformation of the mind, but not of the passion in question. In this case, the mind cultivates another idea, which is more powerful than the passion in question. It does not improve the passion, but, insofar as the new idea is rational, the mind itself does become more rational as a result. In terms of practice, the better ideas, when they are more powerful than the passions that they oppose, determine the person's behaviour. Spinoza introduces this second kind of transition at E5P8-10 and offers a clear account of them at E5P10S, where he recommends cultivation of the rational affects of nobility and tenacity:

So that we may always have this rule of reason ready when it is needed, we should think and meditate often about common human wrongs and how and in what way they may best be driven away by nobility. (E5P10S)

We should think about tenacity in the same way in order to set aside fear; that is, we should recount in detail and frequently imagine the common dangers of life, and how, by presence of mind and by strength of character they may best be avoided and overcome. (E5P10S)

In these cases, Spinoza does not suggest that we will be able to understand or transform our anger or our fear. Sometimes we will not. Even then, however, he argues that we can cultivate stronger motives, which despite these powerful passions can motivate us.

This, then, is a second way of overcoming highly powerful, irrational motives. In some cases we might understand and so transform the passion. In other cases, we might cultivate a different, more powerful motive while leaving the passion itself untouched. The second way leaves some highly irrational ideas intact, which is why it is not as good as the first way. Spinoza acknowledges this point at the beginning of the scholium:

The best thing, therefore, that we can do while we do not have perfect knowledge of our affects is to conceive of [...] sure maxims of life, to commit them to memory, and to apply them continually to particular cases we frequently meet in life, so that our imagination will be affected by them extensively, and they will always be at hand to us. (E5P10S)

While it does not transform our harmful passions, the second method nevertheless makes us better. It gives our rational motives more power. 


\section{The irrational and the rational in society}

The final pieces of background for the thesis, drawn from the Ethics and the TTP, set up the conditions for transitions in society. As I understand Spinoza, the initial problem that society-and that includes religion as well as governmentmust redress is one of a lack of cooperation. Although reason guides those who are led by it to cooperate, very few are led by reason. Most of us are motivated by passions and, outside of society, passions push us in different directions, can draw us into conflict, and, even when they do not, prevent us from enjoying the benefits of cooperation.

Spinoza presents the problem in these terms in both the Ethics and the TTP.

If men lived under the guidance of reason, each might hold [the right of nature] without any harm to another (by P35C1). However because they are vulnerable to affects (by $\mathrm{P} 4 \mathrm{C}$ ), which far surpass human power, or virtue (by P6), they are often drawn in different directions (by P33) and oppose one another (P34) even while they stand in need of each other's aid (by P35S). (E4P37S2)

It is far from true that everyone can always be led under the guidance of reason alone. For each is drawn by his own delight, and the mind is so often filled with avarice, ambition, envy, anger and so on that no place remains for reason. (TTP, ch. 16 / G3:193)

In both places, this presentation of the problem is part of his account of the social contract whereby he suggests that society mitigates this problem:

[...] if we consider that without mutual aid men must live most wretchedly and without any cultivation of reason, we shall see very clearly that to live, not only securely, but very well, men had to agree in having one purpose. So they brought it about that they would have collectively the natural right each one had to all things. It would no longer be determined according to the force and appetite of each one, but according to the power and will of everyone together. (TTP, ch. 16 / G3:191)

In other words, some degree of reason motivates anyone to want to escape the problem of living a brutish, warring life in a state of nature. Societies are thus formed for mutual benefit.

It is not plausible, though, to suggest that people simply live according to the guidance of reason; most of us cannot. So the above passages really only give half the picture.

I think the preface to the TTP hints at a fuller solution. Spinoza suggests there that although reason is sufficient for avoiding the worst harms of passion, it is not necessary. Something else can do the job, namely whatever involves a kind of "fixed plan" of living:

If men could manage all their things by a fixed plan, or if fortune always favored them, no one would be held by superstition. Often, though, they are driven into such difficulties that they are capable of producing no plan and usually they desire the uncertain goods of fortune; vacillate miserably between hope and fear; and so have a great tendency to believe anything whatever. The mind, when it is in doubt, is easily pushed this way or that 
way, and, all the more easily when it is hung up, shaken by hope and fear.

(TTP, Pref. / G3:5)

Religion is just such a fixed plan. It is a kind of belief that provides steady motivation of a sort that is more powerful, at least, than most passions, and so allows those who are guided by it to enjoy the benefits of society. Reason, of course, also serves as a fixed plan for those who follow it: the truths of reason do not vary. Religion, though, need not itself be rational, so long as it provides a strong motive.

Spinoza takes religion to be based upon powerful ideas of imagination and particularly those that give rise to devotion and wonder:

I have shown that scripture does not teach things through their proximate causes but only describes things in the order and in those phrases by which it can most move men and especially commoners to devotion. For this reason it speaks of God and things quite improperly, because undoubtedly its aim is not to convince reason but to affect and occupy men's fancy and imagination. For if scripture described the ravaging of some state in the way customary of political historians, this would do nothing to move the common people. On the other hand, it will move them the most if, as it customarily does, it embellishes everything poetically and refers it to God. (TTP, ch. 6 / G3:91)

There is no doubt that all things that are described in scripture happened naturally but that nevertheless they are attributed to God because it is not for scripture, as we have already shown, to teach things through natural causes. Rather it is to describe those things that deeply occupy the imagination and this in the method and style which best serves to enhance wonder at things and consequently to impress devotion in the spirits of common people. (TTP, ch. 6 / G3:90)

He is unique. That this also is absolutely required for supreme devotion, wonder, and love towards God is beyond doubt. For devotion, wonder, and love arise from the excellence of one above the rest. (TTP, ch. 14 / G3:177)

All of these ideas are ideas of the unique. Chapter 6 of the TTP, the source of the first two passages, is Spinoza's account of miracles, unique events in nature. Although Spinoza denies that there are miracles, he nevertheless takes belief in miracles to be a foundation of religious belief. Religious belief is characteristically devotion and wonder, and those passions arise from the idea of a unique thing. Similarly, I think, Spinoza defends imaginative monotheism in these terms in Chapter 14. Belief in a single god is a more powerful idea than beliefs in several gods. There, also, he refers to devotion and wonder.

Turning to the Ethics, we can see that these ideas-ideas of the unique-do provide strong motives and that they do so in very nearly the same way that reason does. At E3P52 and its scholium, Spinoza discusses such ideas. There he refers to the psychology of association to argue that a mind that has the idea of a unique thing associates the thing with nothing else and, therefore, is unlikely to move to some different object in the way it does with other ideas. So ideas of the unique stay robustly conscious and powerful in the mind:

If we have previously seen an object together with others, or we imagine it 
has nothing but what is common to many things, we shall not consider it so long as one that we imagine to have something unique.

Dem.: As soon as we imagine an object that we have seen with others, we immediately remember it and the others (by $2 \mathrm{P} 18$ and see also P18S). Thus we move from consideration of the one immediately to the consideration of the other. And the same reasoning applies to an object that we imagine to have nothing but what is common to many things. For we suppose in doing this, that we consider nothing in this object that we have not seen before in others. However, when we suppose that we imagine something unique, which we have never seen before, we are saying nothing but that when the mind considers that object, it has no other thing in it, by which it can be moved from the consideration of this object to the consideration of it. So it is determined to consider it alone. Therefore, if we have previously, etc. (E3P52)

In the proposition's scholium, Spinoza goes on to introduce wonder and devotion as ideas of the unique. This shows, I think, why he takes ideas of miracles to have the power that they do. Of course the etymological relation between wonder ( $\mathrm{ad}$ miratio) and miracle (miraculum) is clear in Latin, making the association more natural. In English, we might call Spinoza's miracles "wonders" in order to secure the same effect:

This affection of the Mind, or this imagination of a singular thing [rei singularis imaginatio], insofar as it is alone in the Mind, is called 'wonder' (admiratio) [...] if we wonder at the prudence, diligence, etc., of a man we love, the love will thereby be greater, and this love joined to wonder or veneration we call 'devotion' (devotio). (E3P52S)

Reason, although for a very different reason, is psychologically similar to the idea of a unique thing. Unique things are always present to mind because the mind associates them with nothing else and so cannot move on from them. Ideas of reason are present to mind because they are ideas of properties common to all things, so that whatever it is that we experience, we continue to have, as part of that experience, ideas of reason:

Affects that arise from or are intensified by reason are, if we take account of time, more powerful than those that are related to singular things that we consider to be absent.

Dem.: We consider a thing to be absent not because of the affect by means of which we imagine it, but because of this, that our body is affected by another affect that precludes the thing's existence (2P17). Therefore an affect which is related [refertur] to a thing that we consider to be absent is not of such a nature that it surpasses the rest of a man's actions and power (see 4P6); but, to the contrary, its nature is such that it can be checked in some way by those affections that preclude the existence of its external cause (4P9). An affect, however, that arises from reason, is related necessarily to the common properties of things (see the definition of reason in 2P40S2), which we always regard as present [quas semper contemplamur ut praesentes] (for there can be nothing that precludes their present existence) and which we always imagine in the same way (2P38). Therefore, such an affect will always remain the same, and consequently (A1), affects that 
are opposed to it and that are not reinforced [foventur] by their external causes, must adapt themselves more and more to it, until they are no longer opposed. To that extent, an affect that arises from reason is more powerful. (E5P7)

It is in virtue of the fact that ideas of unique things stay present to mind that they are particularly powerful ideas. The same is true of ideas of reason. That is why, in the TTP, Spinoza takes religion to be a motivational force comparable to reason. I think that he considers religious ideas that give rise to devotion to have a force comparable to tenacity and nobility. Like these active affects, powerful religious ideas, even if they are not themselves adequate ideas, can help us to resist the motivational power of fear, hatred, and anger and to act instead in ways that are good for ourselves and others.

\section{Theism and the second kind of transition}

Finally we are in a position to see why the first kind of transition cannot work. Without a fixed plan, some kind of motivation strong enough to prevent us from being susceptible to easy changes of mind, we will lose the benefits of society and may fall into conflict.

Ideas of religion are extremely irrational. Ideas of reason are ideas of what is true everywhere and at all times, but ideas of the unique are the other extreme. They are ideas of what is true just once, violations of natural law. And of course, they are false: there are no miracles. Because Spinoza takes knowledge to hold intrinsic value, it is pro tanto harmful to have such irrational ideas. Other things being equal, a person is better off without them: as we have seen, Spinoza takes the second method for attaining greater rationality to be the second-best method as well. Other things are not equal, however. A person without religious ideas who has not yet attained powerful ideas of reason is susceptible to changeable and harmful passions. Any gain to an individual from the loss of these highly irrational ideas would be offset by the new dangers, and of course such a person is an unpredictable threat to others in society.

So change to the passion of the sort that Spinoza recommends at E5P4S is not the way to change imaginative religious behaviour in a society, at least not in the first instance. It is better to follow the recommendations of E5P10S and to cultivate rational motives such as nobility and tenacity. Such ideas may be strong enough motives eventually, in some citizens, to allow them safely to gain the additional benefit of dispensing with imaginative religious beliefs altogether. In manyperhaps most-citizens, I think, Spinoza considers the two sorts of beliefs to run in train, recommending the same kinds of actions, but providing very different sorts of motives for those actions.

This is the conclusion that Spinoza's psychology recommends. Whether there is textual evidence suggesting that he himself arrives at this conclusion is a different issue. I think that there is some.

First, there is the point that for Spinoza genuine religion-as opposed to superstition-recommends the same actions that reason recommends in society. I think that it would not necessarily have to do so if he conceived of the transition from religious motivation to rational motivation as one that starts with the 
abandonment of religion. We might imagine a society with a kind of division of labour reminiscent of that of the Republic, in which many people are guided to do certain kinds of beneficial work from some kinds of ideas and in which other are guided to other kinds of beneficial work from others.

Spinoza's society is not like that. The religious majority and the rational few behave in society in the same way, and religion and reason recommend the same sorts of behaviour. Indeed, at TTP, Chapter 4, Spinoza takes genuine religion to be an interpretation of the common notions and the knowledge of God that we all have: "For the love of God arises from the knowledge of him; the knowledge of him, however must be drawn from common notions certain and known through themselves" (G3:61). The common notions, however, just are ideas of reason. So, although it motivates behaviour through the power of highly imaginative ideas, genuine religion recommends the same sorts of behaviour that reason does. This kind of agreement would seem to be a condition for a steady acquisition of ideas of reason in citizens who at the same time maintain their religious beliefs. If religion and reason recommended different behaviours, such people would be conflicted and so lack a fixed plan, something that Spinoza wants to avoid.

A second possible source of evidence may be found in Spinoza's insistence on a belief in God, which is prominent in the TTP (particularly in the tenets of universal faith of Chapter 14) and is strongly suggested also in some of his correspondence with Oldenburg. There, where he is pressed on the question of whether necessitarianism leads to atheism, Spinoza does not acknowledge any kind of good action that arises from a source other than the belief in God:

The inevitable necessity of things destroys neither divine nor human laws. For the moral lessons themselves, whether they are accepted either in form of law or as judgments from God himself, are nevertheless divine and salutary. (Ep. 75, 1676)

He seems to conceive of citizens either as following the imaginative conception of God or as following the philosopher's conception, but Spinoza does not even contemplate a citizen that followed neither.

Of course, Spinoza might have all sorts of rhetorical and political reasons not to say that one might permissibly not believe in God at all. An insistence that the second sort of transition alone is appropriate in society, however, suggests that Spinoza has a basis in his philosophical convictions for this view: to be a good citizen, one must always be motivated either by a belief in the unique imaginative God of the monotheistic religions or by genuine knowledge of God. On the first sort of transition, citizens might lose their strong motivating belief in an imaginative prince-like god as a first step, just as they detach their passion from an external object as a first step at E5P4S. Then, they would only attain a new strong belief in the God of Part 1 of the Ethics, as a final step. Atheism would in such a case be large and dangerous middle ground, and atheists would be a threat to themselves and others. ${ }^{4}$ 
Spinoza, B. \& Gebhardt, C. (Ed.). (1925/1972). Spinoza opera. Heidelberg: Carl Winter.
1 Perhaps there is a third: a state where the government rules by fear.

2 Translations here are my own. I draw from the original Dutch passages in the standard Gebhardt edition of Spinoza (Spinoza, 1925/1972).

3 Spinoza identifies blessedness with understanding at E5P36, E5P36S, and, most clearly perhaps, at E5P42. He defines 'freedom' (libertas) at E1Def7 in terms of action as a total cause, a notion that, in turn he associates with the possession of knowledge at E3Def2 and E3P1.

4 This paper draws upon Michael LeBuffe, Spinoza on Reason, New York, NY: Oxford University Press, 2017. It presents, in a condensed and, it is hoped, widely accessible form, arguments from chapters 2 and 4 of that work. Versions of this paper were presented at the North American Spinoza Society meeting at Chicago in 2016 and the Interstices Under-Construction Symposium conference on Spinoza in Auckland in 2017. Thanks to those audiences and especially to Ericka Tucker and Eu Jin Chua. 